\section{El diario Clarín y la "campaña antiargentina": la construcción de un consenso en torno a las violaciones a los derechos humanos}

\section{Micaela ITURRALDE ${ }^{1}$}

Resumo: Este artigo propõe uma indagação acerca do tratamento informativo e da linha editorial realizada pelo jornal diário argentino Clarín, sobre violações de direitos humanos cometidas na Argentina durante o regime militar 1976-1983. O texto está centrado na análise da conjuntura que começa em 1977 e continua em 1978, quando os militares iniciam uma campanha pública dizendo que há uma "campanha anti-argentina" e que as queixas de organismos internacionais pelo quadro dentro da Argentina eram, na realidade, interpretadas como parte da "ameaça subversiva" que se operava desde o interior do país, assim como do próprio exterior. Considerando que a omissão informativa que caracteriza a denúncia de uma "campanha anti-argentina" se refere diretamente à questão da repressão militar, consideramos também que as construções discursivas e representações criadas e difundidas por Clarín neste contexto - caracterizadas por uma adesão total à chamada "luta anti-subversiva" e pela exaltação nacionalista e patriótica (e êxito) em torno da Copa do Mundo de Futebol de 1978 -, constituíram o modo com que o jornal abordou o tema das violações dos direitos humanos.

Palavras-chave: Clarín; direitos humanos; campanha -antiargentina

1 Profesora y Licenciada en Historia por la Universidad Nacional de Mar del Plata. Becaria doctoral Tipo I del CONICET y doctoranda en Ciencias Sociales por el Instituto de Desarrollo Económico y Social y la Universidad Nacional de General Sarmiento - micaelaiturralde@ gmail.com
Resumen: En este artículo nos proponemos indagar el tratamiento informativo y editorial otorgado por el diario Clarín a las violaciones a los derechos humanos cometidas en la Argentina por el régimen militar que gobernó entre 1976 y 1983. Nos abocaremos al análisis de la coyuntura que se abre en 1977 y se extiende durante todo 1978, cuando se vuelve recurrente en las intervenciones públicas de los militares la denuncia de una supuesta "campaña antiargentina", en la que los reclamos internacionales por la situación nacional fueron interpretados como parte de la "amenaza subversiva" que operaba desde el interior y el exterior. Dado que la omisión informativa que caracteriza la denuncia de una "campaña antiargentina" refiere directamente a la cuestión de la represión estatal, consideramos que las construcciones discursivas y representaciones creadas y difundidas por Clarín en este contexto, caracterizadas por una adhesión total a la llamada "lucha antisubversiva" y por la exaltación nacionalista y patriótica y el exitismo en torno al Mundial de Fútbol, constituyeron el modo en que el diario abordó el tema de las violaciones a los derechos humanos.

Palabras clave: Clarín; derechos humanos; campaña antiargentina

\section{Introducción}

Durante las últimas décadas en Argentina, tanto en el ámbito académico como fuera de él, el interés por la historia reciente, en particular la de la última dictadura militar, se ha visto significativamente incrementado, dando lugar a numerosas indagaciones que iluminan los diferentes aspectos de la vida política, económica y cultural del período. En este marco, los medios de comunicación en general y la prensa en particular, despiertan hoy la atención de un número de investigadores que han iniciado la empresa de estudiar los comportamientos, las actitudes y las estrategias puestas en marcha por los diferentes medios de difusión de la época y sus consecuencias para el régimen militar y la sociedad que gobernaba.

$\mathrm{Al}$ respecto, consideramos que existe una estrecha relación entre prensa y dictadura militar que es necesario dilucidar y explicar, evitando las poco históricas y nada complejas etiquetas de "víctimas" o "colaboracionistas" que, a nuestro entender, empobrecen la investigación académica e impiden el necesario debate que en 
la sociedad debe darse en torno al comportamiento de los diferentes actores políticos durante el llamado Proceso de Reorganización Nacional (1976-1983). Desde esta óptica, nos proponemos analizar el diario Clarín ${ }^{2}$, teniendo en cuenta su importancia como formador de opinión pública en tanto periódico de mayor tirada a nivel nacional ${ }^{3}$, indagando acerca de las representaciones y construcciones simbólicas elaboradas y difundidas por el matutino sobre la represión estatal y las violaciones a los derechos humanos 4 .

Consideramos que la prensa, lejos de ser un mero registro de lo que sucede en una sociedad, constituye un productor de primer orden de las representaciones sociales $^{5}$ que se elaboran en torno a los diferentes temas que en ella se abordan. Los diarios intervienen así en el espacio público, como actores políticos (Borrat, 1989), puestos en relaciones de conflicto o de colaboración con

2 El 28 de agosto de 1945 sale a la venta el primer número de Clarín que fue fundado, con el lema "Un toque de atención para la solución argentina de los problemas argentinos" por el abogado y político Roberto J. Noble. Desde su aparición, el matutino, de formato tabloide, tuvo una carrera ascendente, en la que logró, pese a su oposición al gobierno de Juan Domingo Perón, captar una amplia masa de lectores y de avisos clasificados, que fueron fundamentales en su consolidación como empresa. Desde fines de los '50 hasta la década del ' 80 , Clarín apoyó manifiestamente el ideario político del desarrollismo encabezado a nivel nacional por Rogelio Frigerio y Arturo Frondizi. En los '70 y hasta 1982, esta vinculación se concretó en una alianza ideológica, política e incluso financiera con el partido que aglutinaba al pensamiento desarrollista nacional, el Movimiento de Integración y Desarrollo (MID). A causa del fallecimiento de Noble en enero de 1969, su esposa, Ernestina Herrera, se hizo cargo de la dirección del diario, la cual ha ejercido hasta la actualidad.

3 Para el período que analizamos, Octavio Getino proporciona las siguientes cifras, basadas en un estudio de la UTPBA, de tirada de diarios respectivamente en 1970/1980/1990: 425.900/539.800/552.000 ejemplares diarios. Este autor asimismo destaca que Clarín experimentó un aumento de la venta neta y del porcentaje sobre el total de consumo de diarios, pasando del 22\% en 1970 al 31\% en 1980. Getino, Octavio, Las industrias culturales en la Argentina, Buenos Aires, Colihue, 1995, p.90.

4 Para esto, hemos seleccionado un corpus conformado tanto por editoriales, notas de las secciones Política y Opinión, tapas y titulares, dado que consideramos que toda la superficie redaccional del diario nos permite conocer su posicionamiento discursivo y las estrategias mediáticas puestas en práctica.

5 Siguiendo a Alejandro Raiter entendemos a las representaciones sociales como "imágenes (inmediatas) del mundo presentes en una comunidad lingüística cualquiera", cuyos "emisores institucionales por excelencia (en la época actual) son el sistema educativo en general y los medios" dada su capacidad para establecer lo que denomina Agenda, es decir, "las representaciones activas en un momento dado". Raiter, Alejandro, Representaciones Sociales, Buenos Aires, EUDEBA, 2001, cap. 1. otros actores, en función de su labor de producción y comunicación pública de narrativas y discursos que configuran determinadas interpretaciones de lo sucedido en una sociedad.

El golpe de Estado del 24 de marzo de 1976: “un final inevitable" 6

El 24 de marzo de 1976, Clarín tituló en tapa la llegada de un "NUEVO GOBIERNO”, ante lo que señaló como el "alejamiento de María E. Martínez de Perón como presidente de la Nación" y la "asunción del control del país por una junta militar” (Clarín, 24/3/1976, tapa). El matutino había iniciado la construcción discursiva del golpe ya en los últimos meses de 1975, endureciendo su posición crítica respecto de la administración peronista, presentando la intervención de las Fuerzas Armadas (en adelante FFAA) como inevitable y desacreditando los planes que incluían algún tipo de traspaso legal del poder para salir de la crisis, entre otras estrategias discursivas analizadas por varios autores ${ }^{7}$. La exposición de los hechos presente en las tapas, noticias y editoriales de los días y meses sucesivos al golpe ${ }^{8}$, estuvo dirigida a responsabilizar al propio gobierno de la viuda de Perón por su destitución, a presentar a las FFAA como las necesarias garantes del "orden" y de la "seguridad nacional", a destacar la "serenidad", "precisión” y "rápida vuelta a la normalidad" que caracterizó al derrocamiento, al que el diario se refirió utilizando toda una serie de eufemismos?.

En resumen, la estrategia discursiva de Clarín estuvo destinada en este contexto a legitimar la intervenci-

6 Ese fue el título elegido para el editorial publicado en Clarín el 25 de marzo de 1976.

7 Blaustein Eduardo y Zubieta Martín, Decíamos ayer: la prensa argentina bajo el Proceso, Buenos Aires, Colihue, 1998; Díaz, César, La cuenta regresiva. La construcción periodística en el golpe de 1976, Buenos Aires, La Crujía, 2002; Borrelli, Marcelo, Hacia el "final inevitable". El diario Clarín y la "caída" del gobierno de Isabel Perón (1975-1976). Tesis de Maestría en Comunicación y Cultura. Facultad de Ciencias Sociales, Universidad de Buenos Aires (mimeo), 2008.

8 Clarín, 24/3/1976, 25/3/1976, 26/3/1976, 28/3/1976, 1/04/1976, $19 / 4 / 1976$.

9 Algunas de las palabras con las que el diario se refirió al golpe de Estado, en particular durante los primeros años del "Proceso" fueron: cambio, paso trascendental, movimiento, movilización, sustitución de autoridades, nuevo gobierno, asunción de las Fuerzas Armadas, reemplazo de un régimen agotado e incluso revolución, proclama, acción iniciada en marzo de 1976. Suponemos que del modo de nombrar al "Proceso" por el diario se desprende la caracterización que el matutino hacía de este, la cual, sufrió variaciones conforme el régimen fue perdiendo legitimidad. 
ón de las FFAA en el escenario político y lo hizo, entre otras operaciones, invocando la teoría del "vacío de poder", aludiendo al argumento del "caos económico y social" y citando (y magnificando) el peligro de la amenaza de la "subversión terrorista". A través de las operaciones discursivas analizadas, medios de comunicación como Clarín actuaron como amplificadores de los argumentos militares para concretar el golpe y promover los objetivos del "Proceso", instalándolos y reproduciéndolos en el espacio público.

Al igual que otras garantías constitucionales, el ejercicio de la libertad de prensa fue suprimido durante el gobierno militar, profundizando la censura que ya había sido impuesta desde 1974 por el gobierno peronista. No obstante, la autocensura, es decir una clase de censura previa que limita desde la misma redacción el trabajo periodístico y lo adapta a las necesidades políticas, ideológicas y comerciales de cada medio, fue, durante la dictadura, el mecanismo por excelencia que permitió a gran parte de los medios omitir ciertas informaciones y evitar abordar aquellos "temas sensibles" como los relacionados con el terrorismo de Estado y las disputas al interior del régimen.

La imagen de la "subversión": construyendo una otredad negativa

La llamada, en el discurso militar, "lucha contra la subversión” fue como señala Hugo Quiroga, la base de la estrategia de legitimación del régimen castrense instaurado el 24 de marzo y el factor aglutinante y de mayor consenso entre las diferentes facciones que operaban al interior del mismo (Quiroga, 2003). Siguiendo la periodización del gobierno de facto propuesta por este autor ${ }^{10}$, y concentrándonos en la etapa de "legitimación" (1976 a mediados de 1978) analizaremos de qué manera los discursos y representaciones producidos y difundidos por el diario Clarín colaboraron en la legitimación frente a la sociedad de la represión, tanto legal como ilegal y clandestina, de las organizaciones armadas. Antes de iniciar el análisis, conviene recordar que la comunicación acerca de los temas relacionados con la actividad de la guerrilla sufrió durante el período analizado ciertas limitaciones entre las que encontramos la Ley 20840, dictada durante la administración peronista, que sancionaba a los medios

10 Quiroga distingue cuatro etapas: la de "legitimación" (1976-mediados de 1978); la de "deslegitimación" (mediados de 1978-1979); la de "agotamiento" (1980-1982) y la de "descomposición” (desde junio de 1982 hasta el retorno a la democracia). que se refirieran a las organizaciones armadas por sus nombres, y el comunicado No19 del 24 de marzo de 1976 que preveía la pena de reclusión por tiempo indeterminado para quien "por cualquier medio difundiere, divulgare o propagare comunicados o imágenes provenientes o atribuidas a asociaciones ilícitas o a personas o a grupos notoriamente dedicados a actividades subversivas o de terrorismo" (Varela, 2005, disponível em http://www. camouflagecomics.com).

Siguiendo el discurso militar y al igual que muchos otros medios de prensa de la época ${ }^{11}$, Clarín interpretó el contexto nacional en que se produjo el golpe en los términos de una "guerra civil internacional" (Clarín, 29/7/1976, Editorial "Acción civil de las Fuerzas Armadas", p. 6) iniciada por la "subversión". El matutino se apropió del aparato ideológico y discursivo creado por las FFAA, reproduciéndolo y a su vez, contribuyendo desde sus páginas a su elaboración y puesta en circulación. El periódico presentó una definición de la figura de la "subversión” y de los "subversivos" que buscó imponerse a la sociedad de la época como representación principal del "otro negativo" (Feierstein, 2008, p.78). La acción de los grupos armados fue definida en el diario en los términos de "cobarde atentado criminal", "infernales procedimientos", "anónimos, arteros y cobardes atentados ajenos a la hombría tradicional de los argentinos", "espiral de violencia", "hechos criminales", "bárbaro atentado", "deleznables medios empleados", "cobardes atropellos", "terror". El "enemigo subversivo" fue caracterizado como

una fuerza disolvente (que) esgrime como valores propios - que no solo repugnan al ser nacional argentino sino que también son rechazados universalmente, - tales como el desprecio por la vida humana, la justificación de cualquier medio para cumplir sus fines, alcanzar un poder "revolucionario" totalizador ajeno a los requerimientos de nacionalidades e individuos" (Clarín, 27/3/1977, Editorial "Ganar la paz", p.12).

Estas particularidades del "enemigo" justificaban para Clarín adoptar algunas medidas excepcionales

11 En Nos/otros y la violencia política, César Díaz, Marta Passaro y Mario Giménez, analizan el modo en que la cuestión de la violencia política y el terrorismo de Estado fue abordado por los diarios Buenos Aires Herald, El Día y La Prensa entre 1974 y 1982. 
para derrotarlo. La introducción de la pena capital era una de ellas, ya que según el diario la "acción subversiva" era "una empresa que desborda las previsiones de un ordenamiento legal adecuado para situaciones hoy sobrepasadas, (y) justifica sin duda la necesidad de recurrir a una mayor severidad represiva" (Clarín, 28/6/1976, Editorial "Precisiones sobre la violencia", p.6). Asimismo veía necesario consolidar el monopolio de la fuerza dado que la "guerra (...) exige una concentración de poder y de violencia muy altos" (Clarín, 28/6/1976, Editorial "Precisiones sobre la violencia", p.6).

Para Clarín se trataba de una "guerra global" que tenía un "carácter socialmente total", dado que involucraba a todos los sectores, y que conllevaba a que sea "la Nación la que está en armas para vencer al enemigo" (Clarín, 1/8/1976, Editorial "El principio del fin”, p.10). La Nación, o más frecuentemente en el matutino, "el ser nacional", fue el colectivo de identificación al que se dirigieron los editoriales del diario, el cual actuó como un “nosotros inclusivo" (Verón, 1987, p. 17) frente al "otro negativo" definido como la "subversión". Ambos conformaron el binomio fundamental sobre el que se basó el relato presentado por el diario y en el que las FFAA no sólo formaban parte del "ser nacional" sino que, como se afirma en un editorial claramente apologético de la institución

contribuyen significativamente a configurar el ser nacional, cuyo perfeccionamiento y consolidación aparece como la idea-fuerza que mueve al actual proceso de recuperación nacional. No se trata solo de las guerras por la Independencia o de la Conquista del Desierto, sino al mismo tiempo de la labor cumplida por la unificación espiritual y material de la Nación, en la tarea civilizadora, en su presencia en la comunidad como parte y reflejo de toda ella, como bastión último que defiende la integridad del país y no ceja en la lucha por su integración (Clarín, 29/7/1976, Editorial "Acción civil de las Fuerzas Armadas", p.6).

La "subversión" fue representada en Clarín no sólo como absolutamente ajena a ese "ser nacional", señalándose que "lo cierto y rescatable es que en ningún momento tuvo ella apoyo logístico, moral o material de la población", sino además como un accionar deshu- manizado y despersonalizado ${ }^{12}$. Coincidimos con Daniel Feierstein en que esta "deshumanización del otro" permitió, tanto en el caso de los mismos perpetradores como de aquellos que legitimaron su accionar, derribar las barreras morales inherentes a las acciones de secuestrar, torturar, violar y asesinar. En el caso del diario, la hegemonía del discurso de la guerra y de la representación del "subversivo" como el "otro negativo no-normalizable" permitió probablemente neutralizar, al menos por algunos años, el impacto que pudiera tener sobre los lectores la permanencia de la violencia, la desaparición y la muerte de personas en sus páginas. Este "anestesiamiento moral" (Novaro; Palermo, 2003, p.134) unido a la clandestinización de la represión, explica, en parte, la actitud prescindente de gran parte de la sociedad ante las violaciones a los derechos humanos que tenían lugar en el país.

El relato acerca de la violencia política construido y difundido por el diario presentó como legítima la respuesta represiva régimen, tanto en su versión legal como ilegal. Respecto de la primera, el diario exigió desde 1975 la intervención de las FFAA para poner orden a una situación que entendía como de extrema crisis, y luego de ocurrido el golpe, señaló que "el establecimiento del monopolio de la fuerza por parte del Estado es hoy más que nunca un objetivo prioritario. Porque solo en manos del Estado, es decir, ejercida con responsabilidad y por personas autorizadas, la fuerza puede alcanzar el prestigio de necesario auxiliar de la justicia" (Clarín, 19/6/1976, Editorial "El asesinato del jefe de Policía", p.6). La justificación al uso de los métodos que las FFAA llamaron "no convencionales" apareció señalada en el diario en un editorial aparecido luego de una serie de atentados realizados por las organizaciones armadas en el que se afirmaba que "La falta de actividad orgánica de la subversión obliga más que nunca a dar a la represión un contenido no conformista. No se lucha contra los enemigos del ser nacional argentino para fijar a la sociedad en el pasado sino para impulsarla hacia adelante" (Clarín, 10/4/77, Editorial "Los fines y los medios",

12 En su columna editorial del día siguiente al atentado a la casa del almirante Armando Lambruschini el diario afirmaba: "No es ésta la primera oportunidad en que emitimos nuestro juicio frente al accionar del terrorismo señalando que esa acción criminal cobra víctimas en forma indiscriminada, lo cual revela que sus sicarios, en la búsqueda desesperada de fines, exponen la carencia absoluta de los más elementales atributos de la condición humana". Editorial "Ante el artero atentado”, Clarín, 2/8/1978, p. 10. El subrayado es nuestro. 
p.6, subrayado nuestro). Asimismo, en un editorial de agosto de 1978 titulado "Los derechos humanos", se argumentaba que "Los expedientes de excepción a que fue necesario recurrir, por las modalidades de la batalla empeñada, concitan la comprensión de la ciudadanía que quiere vivir en un ambiente de tranquilidad y paz, segura de que puede trabajar, pensar y expresarse con entera libertad dentro de normas pluralistas de convivencia y sin temor a los ataques arteros de los extremismos de izquierda y derecha que buscan violar su forma de vida" (Clarín, 18/8/1978, Editorial "Los derechos humanos", p. 6, subrayado nuestro). La nota venía a justificar los denominados "excesos", según el discurso militar, el cual había debido reconocer en esos meses que la represión no se había dado enteramente en forma controlada y legal.

Asimismo, los discursos y las representaciones acerca de la violencia política presentes en el diario Clarín entre 1976 y 1978 dieron legitimidad al accionar represivo de las FFAA y favorecieron la llamada "lucha antisubversiva", en las dos etapas que le asignó el régimen militar. En el plano de la represión propiamente militar, lo hizo legitimando el accionar militar y exigiendo el monopolio de las fuerza en las FFAA, no publicando hasta 1980 las denuncias de los organismos nacionales de derechos humanos, dando información falsa sobre supuestos enfrentamientos entre las organizaciones armadas y las "fuerzas de seguridad" y sobre sus consecuencias ${ }^{13}$, presentando datos erróneos que sobredimensionaban la capacidad de las guerrilla y engrosaban las cifras de la violencia provocada por su accionar ${ }^{14}$, publicando informaciones tendientes a fracturar internamente a las

13 Un ejemplo lo constituye el caso del secuestro de Norma Arrostito. El 4 de diciembre de 1976 Clarín titulaba "Abatieron a una cabecilla de la subversión" y la nota de la página 4 informaba que "al resistirse a una orden de detención, fuerzas de seguridad abatieron (...) a Norma Esther Arrostito, fundadora y figura clave de la organización declarada ilegal en 1975" (Clarín. 4/12/1976, p.4). En realidad lo que había ocurrido era su secuestro y traslado a la ESMA. Las FFAA esperaban, con la noticia de su muerte, causar un fuerte impacto entre las filas de Montoneros.

14 Esto se hacía por ejemplo informando que la autoría de resonantes secuestros y asesinatos correspondía a las organizaciones armadas, cuando en realidad en crímenes producidos por las distintas facciones internas de las FFAA. Nos referimos particularmente a los casos de los políticos uruguayos (Zelmar Michelini y Héctor Gutiérrez Ruiz) (21/5/1976), del ex presidente de Bolivia Juan J. Torres (3 y 4/6/1976), del embajador argentina en Venezuela Héctor Hidalgo Solá (18/7/1977) y el de las monjas francesas (Alice Domon y Léoni Duquet) (17 y 18/12/1977). organizaciones armadas y a causar confusión entre sus miembros ${ }^{15}$ y otorgando un amplio espacio al dolor de las familias de las "víctimas de la subversión" y a sus actividades. No obstante también favoreció la realización de lo que las FFAA entendían como una segunda etapa de la "lucha antisubversiva", iniciada luego de su derrota militar. Esta fue descripta por el Teniente General Jorge Rafael Videla quién en el reportaje exclusivo publicado en Clarín el 30 de enero de 1977 señalaba:

En el contexto de la lucha global que hemos encarado, erradicaremos sus causas y eliminaremos sus efectos, saneando todos aquellos campos del cuerpo social que fueron afectados por la acción disolvente de la subversión. Pero nuestro accionar no se limitará a una acción de saneamiento. Por el contrario, más trascendente es aún la afirmación de todos aquellos valores que constituyen el fundamento de nuestra fe cristiana, de nuestra cultura y de nuestra idiosincrasia nacional (...). Para ello propenderemos a la defensa de la dignidad del hombre, el fortalecimiento de la familia como institución fundamental, el enriquecimiento de nuestra educación en contenidos auténticamente argentinos y el retorno a las fuentes de nuestra historia (Clarín, 30/1/1977, p.4, subrayado nuestro).

Clarín se comprometió decididamente en esta tarea de refuerzo de los valores del "ser nacional" y lo hizo publicando editoriales y notas referidas a la valorización de lo propiamente argentino y de la fe cristiana, a la vigorización de la familia como institución fundamental (Clarín, 27/6/1978, Editorial "El rol de la familia", p.6), a la vuelta a los anales de la historia y al ejemplo de los próceres patrios ${ }^{16} \mathrm{e}$ insistió desde sus páginas acerca de la importancia del papel que habría de desempeñar la juventud durante el "Proceso de reorganización $\mathrm{Na}$ cional" ${ }^{17}$, todo esto acompañado de una exaltación de

15 Son frecuentes las noticias publicadas en Clarín, a las cuales se les otorgaba un lugar central en la sección Política, referidas a la reducción de penas a "extremistas" que se presentasen en forma voluntaria y de casos en que esas reducciones realmente se comprobaron. (Clarín, 29/6/1977, p.7; 26/7/1977, p. 9).

16 Editorial "Punto de partida", Clarín 13/5/1977; "Identidad nacional”, 15/5/1977; "La herencia mayor de Mayo", 25/5/1977.

17 Editorial "Juventud y diálogo", Clarín 28/4/1977; "El sector juvenil", 20/5/1977; "Las generaciones", 8/8/1977; "Juventud y Nación”, 25/9/77; “La nueva generación”, 28/10/1977; “Juventud y porvenir", 28/11/1977. 
los valores de la cultura nacional y de un discurso apologético de la actuación histórica de las FFAA y de la "consolidación de la unidad pueblo-Ejército" (Clarín, 29/7/1976, Editorial "Acción civil de las Fuerzas Armadas", p.6). Haciéndose eco de la consigna vertida por los máximos representantes del régimen, en el editorial " $\mathrm{Ga}$ nar la paz" el matutino expuso claramente los campos en los que se debatía la "victoria sobre la subversión":

La paz se gana en tres frentes de batalla. Uno, no puede ser otro que el de la lucha bélica que procura desarmar al enemigo, destruyéndolo o desguarneciéndolo. Los otros dos no son bélicos, aunque la unidad de mando y hasta que se alcance a armar espiritual y materialmente a la Nación hace que la responsabilidad central de gobernar el país descanse principalmente sobre las Fuerzas Armadas, con la colaboración y el consentimiento de todos los sectores sociales. Urge determinar y robustecer la personalidad nacional (...). Y el argentino tiene sólidas razones y sentimientos para lograrlo. Una propuesta de la Iglesia para el año, y que los argentinos debieran arraigar en sus corazones y en sus mentes, afirma que se defienda la Paz defendiendo la Vida. El tercer frente de batalla se refiere a las bases materiales que requiere la afirmación de la Nación en el mundo (...). También aquí la síntesis ya está formulada: 'El desarrollo es el nombre contemporáneo de la paz' (Clarín, 27/3/1977, Editorial 'Ganar la paz”, p.12, subrayado nuestro).

Este último campo, referido al orden de lo económico, pone de manifiesto la importancia que tenía en el matutino la prédica desarrollista adoptada por el MID y sus más importantes representantes. Según este partido, el subdesarrollo característico de la estructura económica argentina constituía asimismo una causa fundamental de la "acción subversiva", otorgando un terreno propicio para su aparición y extensión (Yannuzzi, 1996).

\section{Clarín y la "campaña antiargentina"}

Si en la Argentina el discurso cuasi monolítico presente en los medios durante estos dos primeros años de la dictadura era el de la "guerra interna" y el de la condena a la "subversión", en el exterior, las denuncias de los exiliados y de algunos organismos internacionales ponían en evidencia otra versión de lo que sucedía en el país. La presión internacional en torno a las violaciones a los derechos humanos cometidas por el régimen militar comenzó en 1976, a pocos meses de iniciado el "Proceso", pero aumentó considerablemente entre 1977 y 1978, en particular, en el seno de la Organización de Estados Americanos (OEA) y en la nueva conducción del gobierno norteamericano a cargo de James Carter. La principal respuesta de los militares ante los reclamos fue la denuncia de una supuesta "campaña antiargentina", en cuya elaboración y difusión los medios de comunicación nacionales, entre ellos el diario que analizamos, desempeñaron un papel fundamental ${ }^{18}$.

La referencia a la existencia de una campaña de "descrédito" y "desprestigio" de la Argentina en el exterior, basada en una imagen "falsa", "deformada", "distorsionada" y "alejada de la realidad del país", se inició muy tempranamente en el seno del gobierno de facto, en 1976, pero alcanzó su punto más álgido en 1978 durante los meses previos y la realización del Mundial de Fútbol que tuvo como sede a la Argentina. También tempranamente el diario Clarín se hizo eco de las declaraciones militares, reproduciéndolas y aportando elementos a la denuncia que, en clave conspirativa, se hizo de una llamada "campaña antiargentina". Nuestro interés por la misma refiere a que consideramos que la denuncia de esta campaña internacional de desprestigio constituyó una operación mediática y discursiva encabezada por algunos medios de comunicación nacionales, entre los que destaca el diario Clarín, tendiente a crear consenso en torno al discurso militar sobre las violaciones a los derechos humanos. A la dicotomía básica nosotros/otros que analizamos en el apartado anterior, en esta coyuntura se le superpuso la que oponía dentro/fuera de la Argentina y las diferencias entre las imágenes/representaciones producidas en ambos lugares.

Como señala Marina Franco, gran parte de la prensa nacional puso en marcha una serie de estrategias para contribuir a la denuncia de la supuesta campaña. La extensa transcripción de comunicados, discursos y proclamas del gobierno militar fue una de ellas, la cual además actúo como una constante en los primeros años

18 Para una análisis del accionar de los principales medios de prensa durante la "campaña antiargentina" ver: Franco, Marina, "La `campaña antiargentina': la prensa, el discurso militar y la construcción de consenso", en Judith Casali de Babot y María Victoria Grillo (eds.), Derecha, fascismo y antifascismo en Europa y Argentina, Universidad de Tucumán, 2002, pp.195-225. 
del "Proceso", también en torno a otros temas. Otra estrategia utilizada fue la de "transformar en 'información' o 'noticia' todo aquello que (...) significaba una denuncia de esa 'distorsión' de la imagen Argentina” (Babot; Grillo, 2002). Esto puede observarse en algunas notas publicadas por Clarín en las que se informaban iniciativas de entidades empresariales o de grupos de profesionales e intelectuales destinadas a denunciar la campaña y a rebatir los juicios de la misma ${ }^{19}$.

El espacio editorial de Clarín fue asimismo destinado en sucesivas oportunidades a la denuncia de la campaña, la cual fue caracterizada como "tendenciosa" y "nociva" y definida como un "análisis intencionadamente parcial" que ofrecía una "imagen distorsionada" y que reflejaba un "desconocimiento y hasta una parcial deformación de la realidad" ${ }^{20}$. Esta denuncia estuvo acompañada de importantes críticas a los supuestos promotores de la misma, en particular, a la administración del presidente Carter y a la OEA. Respecto del gobierno norteamericano, el matutino señaló, retomando el discurso militar que interpretaba la presión del gobierno norteamericano por las violaciones a los derechos humanos como una injerencia externa a los asuntos nacionales, que

A partir del cambio de gobierno se advierten síntomas que contradicen la concepción más pragmática impresa a la acción externa por la administración precedente. Una nueva orientación mesiánica parece procurar el desborde de las fronteras que protegen las distintas independencias nacionales. Ello es claramente discernible, al menos con respecto a los países en los cuales ningún interés fundamental de Estados Unidos resulta afectado (Clarín, 9/3/1977, Editorial "Una nueva modalidad", p.6, subrayado nuestro).

Por su parte, la OEA, el principal foro internacional desde el cual partían los reclamos, fue caracterizado en el diario como

un árbol seco que, progresivamente, se va petrificando. Ni la frondosidad burocrática del organismo, ni su trayectoria, ni las ideas que maneja son

19 Clarín, 22/6/1978, p. 4; 24/6/1978, p. 5; 23/8/1978, p. 6 20 Editorial "El asesinato del jefe de Policía"; Editorial "Los derechos humanos", Clarín 16/9/1976, p. 8; Editorial "En torno a los derechos humanos", Clarín, 6/10/1976, p. 6. susceptibles de dar frutos. (...). El tema de los derechos humanos, en la asamblea de Granada, no ha sido enfocado ni en función de las realidades vividas en los países latinoamericanos ni de manera acorde con la construcción de un futuro donde el hombre pueda realizarse, con libertad y decoro, en todos los planos (Clarín, 25/6/1977, Editorial "La OEA en perspectiva", p.6).

Los principales representantes del gobierno militar y los medios de comunicación afines entendieron que era necesario contrarrestar el desprestigio internacional que afectaba a la Argentina y pusieron en marcha toda una serie de operaciones de propaganda destinadas a crear una imagen positiva del país y, por supuesto, del régimen de facto que lo gobernaba. Desde el gobierno, incluso se creó un "sistema para mejorar la imagen del país", integrado por un Centro Piloto en París (uno de los principales emisores de las representaciones "distorsionadas" según las FFAA), un Departamento de Prensa y uno de Difusión al exterior, todos ellos dependientes de la Dirección General de Prensa y Difusión perteneciente al Ministerio de Relaciones Exteriores y Culto (Clarín, 27/7/1977, p.10). No obstante la iniciativa fundamental para presentar una mejor imagen de la Argentina fue la realización en el país del campeonato internacional de Fútbol en junio de 1978. Como señalan Novaro y Palermo, "el Mundial de Futbol era un test decisivo, tanto en lo interno como en lo externo" (2003, p.160), y no sólo los militares lo entendieron de esa manera, sino también algunos medios de comunicación, como Clarín, que se lanzaron a la realización de una contracampaña, es decir, de una "campaña proargentina".

Casi un año antes de la realización del Mundial, en un editorial dedicado al tema, Clarín exponía ya claramente los objetivos que rodeaban la realización del campeonato señalando que

El acontecimiento constituye un desafío que se despliega en amplia gama (...). Es una oportunidad nada desdeñable para mejorar la deteriorada actual imagen nacional (...). Hay que reconocerlo. No es justamente en las cifras del score donde puede estar la mayor ganancia de la Argentina, a favor del Mundial. Ganaremos, ganando amigos (Clarín, 14/7/1977, Editorial “El Mundial”, p. 10)

111 
Estas intervenciones se volvieron más frecuentes en los meses previos y durante la realización del campeonato, coyuntura en la cual la "campaña proargentina" se desplegó en las diferentes secciones del diario, desde Política hasta el Suplemento Deportivo ${ }^{21}$, pasando por la columna editorial. El matutino publicó entrevistas y comentarios positivos de los visitantes al país que desmentían la campaña externa de desprestigio (Clarín, 2/6/1978, p.6; 5/6/1978, Suplemento Deportivo, p.8-9; $7 / 7 / 1978$, p.5), muestras varias del fervor y la unidad nacional en torno al evento y a sus realizadores ${ }^{22}$, y notas y editoriales escritos en un tono nacionalista y triunfalista cargados de exaltaciones patrióticas. Uno de ellos, titulado, "El país puede hacerlo" ejemplifica la retórica del momento:

El fervor nacional, apoyado en el culto al deporte popular por excelencia, se apoya en esta circunstancia en el deseo manifestado por la hinchada en las tribunas, por el pueblo en general en las calles, el periodismo - especializado o no - en las nutridas columnas aparecidas en los órganos de prensa en estos días y expresado en los otros medios de comunicación, de exhibir ante el mundo entero una imagen adecuada de la Argentina. Constituye éste un rasgo del ser nacional, el orgullo digno de ser rescatado y aplicado racionalmente a otras zonas del quehacer (...). Hemos comprobado, una vez más, que el ser nacional existe y tiene acusadas características (Clarín, 18/6/1978, Editorial "El país puede hacerlo", p.6)

Consideramos que la principal omisión informativa de esta "campaña proargentina" refiere directamente a la represión estatal y a las violaciones a los derechos humanos cometidas por el régimen militar. En simultáneo con la realización del campeonato, en la OEA se trataba el caso nacional y el 20 de junio de 1978, el canciller argentino vicealmirante Oscar Montes invitaba a la Comisión Interamericana de Derechos Humanos a visitar la Argentina. Si bien la denuncia de la "campaña antiargentina” que realizó Clarín no eludía la cuestión de

21 Durante junio de 1978, el mes de realización del campeonato, el matutino publicó un suplemento titulado Clarín Mundial, enteramente dedicado al acontecimiento.

22 En este sentido, las tapas y sus titulares, por su disposición poco frecuente y la carga simbólica de las fotografías, son elocuentes: Clarín, 2/6/1978; 25/6/1978; 26/6/1978;27/6/1978. las violaciones a los derechos humanos, la interpretaba de una manera diametralmente opuesta a la denunciada.

Las representaciones en torno a una "campaña antiargentina" aparecidas en el diario proponían al lector una visión diferente respecto de las violaciones a los derechos humanos que la que esgrimían los foros internacionales, EEUU y algunos países europeos y los organismos defensores de estos derechos en el plano internacional y nacional. Estamos en desacuerdo con Marina Franco cuando afirma que "el tema de los derechos humanos aparece sistemáticamente en la prensa en la cobertura informativa donde se recogen declaraciones de funcionarios militares y acontecimientos internacionales; sin embargo, no necesariamente aparece asociado a la ‘campaña antiargentina' y a su denuncia como discurso propio de la prensa o como 'palabra apropiada"'(FRANCO, 2002, p.223). Por el contrario, observamos en los editoriales de Clarín la recurrencia de una explicación que enlaza la denuncia de la "campaña antiargentina" con la cuestión de las violaciones a los derechos humanos, aunque esta última aparezca interpretada desde una óptica opuesta a la de los organismos de derechos humanos.

Esta lectura puede leerse por ejemplo en el matutino en un editorial publicado con motivo de las sanciones impuestas por el gobierno norteamericano a la Argentina por las violaciones a los derechos humanos:

La Argentina aparece siendo objeto de sanciones. Frente a la sanción no hay alternativa válida. (...). Pero al mismo tiempo urge que los argentinos midamos el significado de la creciente difusión de una imagen del país que no muestra ni a su ser nacional ni refleja su tradición de respeto por los derechos humanos (...). El triunfo sobre la subversión - de notable infiltración extranjera - implica también el imperio natural de los derechos humanos. No para satisfacción de los poderosos del mundo, que los invocan, muchas veces equivocadamente, sino como objetivo nacional (Clarín, 26/2/1977, Editorial "Frente a una sanción", p.6)

La versión presentada por Clarín no negaba la existencia de violaciones a los derechos humanos en el país, pero sí que éstas hubiesen sido cometidas por otros que no fuesen las organizaciones armadas. Afirmaba entonces que 
Para la guerrilla los derechos humanos no existen y solo se aduce su vigencia cuando se trata de cubrir con la impunidad una extensa sucesión de incalificables delitos. Una actitud similar se advierte en cierta prensa extranjera que ha elegido como blanco a la Argentina con el pretexto de que sus autoridades no respetan los derechos humanos (...). Mientras los atropellos de la subversión son sistemáticamente silenciados, las acciones que tienden a reprimirlos son presentadas como un ejercicio de brutalidad policial y como una flagrante violación a los derechos humanos (Clarín, 16/9/1976, Editorial "Los derechos humanos", p.8)

En otro lugar se refuerza esta idea, diferenciando claramente el accionar del Estado de cualquier violación a los derechos humanos: "El peso de la violación de los derechos humanos por parte de la agresión que llevó al país a la guerra que transcurre, atrae sobre sí la capacidad defensiva y represiva del Estado" (Clarín, 8/3/1977, Editorial "Claridad conceptual", p.8).

Consideramos entonces que las construcciones discursivas y las imágenes creadas y difundidas por Clarín con motivo de la denuncia de la "campaña antiargentina" propusieron una nueva lectura en torno a las violaciones a los derechos humanos, en la cual la "subversión" aparecía como principal ejecutora de las mismas y el "ser nacional" como su víctima inocente. En el contexto de la "campaña antiargentina" y de preparación y realización del Mundial de Fútbol, las representaciones producidas y puestas en circulación por el diario en torno a las violaciones a los derechos humanos, hicieron referencia alternativamente a:

- El accionar de la llamada "subversión" y sus consecuencias para la sociedad argentina.

- Una campaña de desprestigio internacional para dañar la imagen del país.

- Una excusa de la administración Carter para intervenir en el gobierno argentino.

- Si eran cometidas por el Estado, referían a una realidad que tenía lugar en otros países como Chile, Paraguay o Uruguay.

Consideramos que esta construcción discursiva sobre el tema de las violaciones a los derechos humanos puede ser interpretada como parte de las intervenciones públicas del diario, las cuales constituyen elementos fundamentales para el análisis de las relaciones negociación y acuerdo que establecieron los medios de prensa con las autoridades gobernantes durante la dictadura. Medios como Clarín, conscientes de su influencia en la opinión pública, entablaron una serie de acuerdos con los representantes del régimen castrense que les permitieron obtener importantes beneficios económicos y empresariales, entre los que destaca la participación en la empresa estatal Papel Prensa ${ }^{23}$, mientras que aceptasen las restricciones que pesaban sobre la información y colaborasen desde sus páginas con la legitimación del régimen y de sus proyectos "refundacionales". Además de los beneficios empresariales obtenidos, consideramos que en la explicación de la línea editorial del diario en estos primeros tres años del "Proceso" debe tenerse en cuenta la activa participación de miembros del MID en la redacción y la postura que este partido había adoptado respecto de la dictadura (Yannuzzi, 1996). Este partido interpretó al Proceso de Reorganización Nacional como el advenimiento de una "revolución nacional" (MID, 1981, p. 97), términos que replicará en sus páginas el diario de Noble. El MID fue el único partido nacional que se abocó sin reparos a apuntalar al régimen militar, celebrando el advenimiento del mismo y su programa refundacional, en particular, en el terreno de lo que los militares llamaron la "guerra sucia contra la subversión". No obstante este apoyo pareció estar condicionado a la implementación del programa económico desarrollista, y se irá diluyendo conforme el rumbo económico trazado por el ministro Martínez de Hoz choque de frente con las premisas industrialistas, intervencionistas y nacionalistas de los hombres del MID. De acuerdo con la línea adoptada por el desarrollismo nacional, el diario de Noble mezclará el discurso apologético respecto de la "lucha antisubversi-

$23 \mathrm{El}$ abastecimiento de papel prensa era, y lo había sido durante décadas, uno de los problemas principales con los que debía lidiar la prensa gráfica argentina. Recuperando un proyecto iniciado durante el Onganiato y llevando a cabo un viejo anhelo de los diarios nacionales, la dictadura militar ofreció a los diarios Clarín, La Nación, La Razón y La Prensa, por entonces los de mayor tirada a nivel nacional, asociarse con el Estado, en la compra del paquete accionario de la empresa Papel Prensa S.A, productora del valorado insumo y propiedad de David Graiver, muerto a mediados de 1976 en un sospechoso accidente de avión y quién se desempeñaba como "banquero" de los dineros obtenidos por la agrupación Montoneros en sus actividades ilícitas. Para ampliar ver: Borrelli, Marcelo, “Una batalla ganada': el diario Clarín frente a la compra de Papel Prensa por parte de los diarios La Nación, Clarín y La Razón (1976-1978)", en Papeles de trabajo, N4, Buenos Aires, Idaes, 2008. 113 
va" y los planes políticos del "Proceso" con el admonitorio y crítico para caracterizar la política economía liberal.

Para la realización de los objetivos instaurados por las FFAA el 24 de marzo de 1976, la elaboración de un dispositivo ideológico que los difundiera, justificara y presentara como legítimos ante la sociedad resultaba fundamental. Respecto de la implementación de un plan sistemático de represión, durante al menos los tres primeros años del régimen, el diario Clarín contribuyó con esa tarea, reproduciendo en el limitado espacio público las principales consignas militares y favoreciendo el ocultamiento y la negación pública de los crímenes producto de la implementación del Terrorismo de Estado. Lo hizo a través de la construcción de una figura de la "subversión" representada como una otredad negativa, que era necesario erradicar y eliminar de la sociedad argentina, y por medio de un discurso que combinó la ponderación y justificación del accionar represivo del régimen con una negación de las voces críticas provenientes del interior y una descalificación de las exteriores.

La denuncia de la "campaña antiargentina" realizada por el diario constituyó el punto de mayor elaboración y difusión de este discurso, dado que en ella confluyeron la visión demonizada de las organizaciones armadas y las loas a la represión estatal para dar forma a una interpretación de las violaciones a los derechos humanos claramente reñida y enfrentada a la denunciada por los organismos nacionales e internacionales especializados en la materia y por los exiliados. La cuestión de las violaciones a los derechos humanos fue rápidamente reinterpretada desde las páginas del matutino que ofreció un relato centrado en la denuncia de los "crímenes" cometidos por el "accionar subversivo", la injusticia y el dolor por las muertes de "víctimas inocentes de la subversión", lo que exigía y otorgaba crédito a la respuesta represiva puesta en marcha por el régimen para contrarrestar esa violencia representada como unidireccional.

\section{Referencias}

BLAUSTEIN, Eduardo; ZUBIETA, Martín. Decíamos ayer: la prensa argentina bajo el Proceso. Buenos Aires: Colihue, 1998.

BORRAT, Héctor. El periódico, actor político. Barcelona: Gustavo Gili, 1989.
BORRELLI, Marcelo. 'Una batalla ganada': el diario Clarín frente a la compra de Papel Prensa por parte de los diarios La Nación, Clarín y La Razón (1976-1978)”. IN: Papeles de trabajo, n.4. Buenos Aires: Idaes, 2008.

Hacia el "final inevitable". El diario Clarin y la "caída" del gobierno de Isabel Perón (1975-1976). Tesis de Maestría en Comunicación y Cultura. Facultad de Ciencias Sociales, Universidad de Buenos Aires (mimeo), 2008.

DÍAZ, César (Org.). La cuenta regresiva. La construcción periodística en el golpe de 1976. Buenos Aires: La Crujía, 2002.

(Org.). Nos/otros y la violencia política 1974-1982.

La Plata: Ediciones Al Margen, 2009.

FEIERSTEIN, Daniel. El genocidio como práctica social. Entre el nazismo y la experiencia argentina. Buenos Aires: Fondo de Cultura Económica, 2008.

FRANCO, Marina. 'La 'campaña antiargentina': la prensa, el discurso militar y la construcción de consenso". IN: CASALI DE BABOT, Judith; GRILLO, María Victoria (Orgs.). Derecha, fascismo y antifascismo en Europa y Argentina. Universidad de Tucumán: 2002, pp.195-225.

GETINO, Octavio. Las industrias culturales en la Argentina. Buenos Aires: Colihue, 1995.

MID. La crisis argentina. Buenos AiresL: 1981.

NOVARO, Marcos; PALERMO, Vicente. La dictadura militar (1976-1983). Buenos Aires: Paidós, 2003.

QUIROGA, Hugo. El tiempo del "Proceso". Conflictos y coincidencias entre políticos y militares 1976 - 1983. Rosario: Homo Sapiens, 2003.

RAITER, Alejandro. Representaciones Sociales. Buenos Aires: EUDEBA, 2001.

VARELA, Mirta. "Los medios de comunicación durante la dictadura: entre la banalidad y la censura". IN: Camouflage Comics. Censorship, Comics, Culture and the Arts - disponível em http://www.camouflagecomics.com, acesso em 10/04/2012. 
VERÓN, Eliseo. La semiosis social. Buenos Aires: Gedisa, 1987.

YANNUZZI, María de los Ángeles. Política y Dictadura. Rosario: Fundación Ross, 1996.

Recebido: 07/03/2012

Aprovado: 09/04/2012 